\title{
ENTREVISTA
}

\section{PERE GABRIEL, INICIADOR DELS ESTUDIS SOBRE EL MOVIMENT OBRER A LES BALEARS}

Pere Gabriel i Sirvent (Terrassa, 1945) és un dels pioners de la historiografia científica sobre les Balears. Dos anys abans de la mort de Franco, va publicar El moviment obrer a Mallorca (Curial-Lavínia, Barcelona, 1973), llibre emblemàtic, que implicà una reinterpretació global de la història política i social de preguerra. Per primera vegada, hom trencà amb el tòpic de l'illa de la calma i descobrí l'existència d'una realitat complexa marcada per un desenvolupament urbà i industrial gens menyspreable, que havia posat les bases per a la difusió del republicanisme i l'obrerisme a Mallorca. A hores d'ara, El moviment obrer... és encara un referent crucial per als estudiosos dels segles XIX i xx a l'arxipèlag.

Des d'aleshores, Pere Gabriel ha desplegat una extensa i innovadora obra centrada en l'estudi
David Ginard i Féron

Universitat de les Illes Balears de l'obrerisme i el republicanisme a Espanya i a Catalunya, alhora que ha mantingut un contacte permanent amb les Illes per raons professionals i familiars (la seva dona, la professora i historiadora de la literatura Margalida Tomàs i Vidal, és mallorquina). En són un bon exemple les col-laboracions en la revista Randa o la participació en jornades i actes acadèmics organitzats per l'àrea d'Història Contemporània de la Universitat de les Illes Balears. El 2015 es jubilà com a catedràtic d'Història Contemporània de la Universitat Autònoma de Barcelona, després de gairebé quatre decennis de plena activitat com a docent i investigador. És ara catedràtic emèrit. No hi ha dubte, per tant, que es tracta d'una persona ben idònia per encetar aquesta secció, en què historiadors consagrats vinculats amb les Balears proporcionaran un balanç de la seva experiència professional.

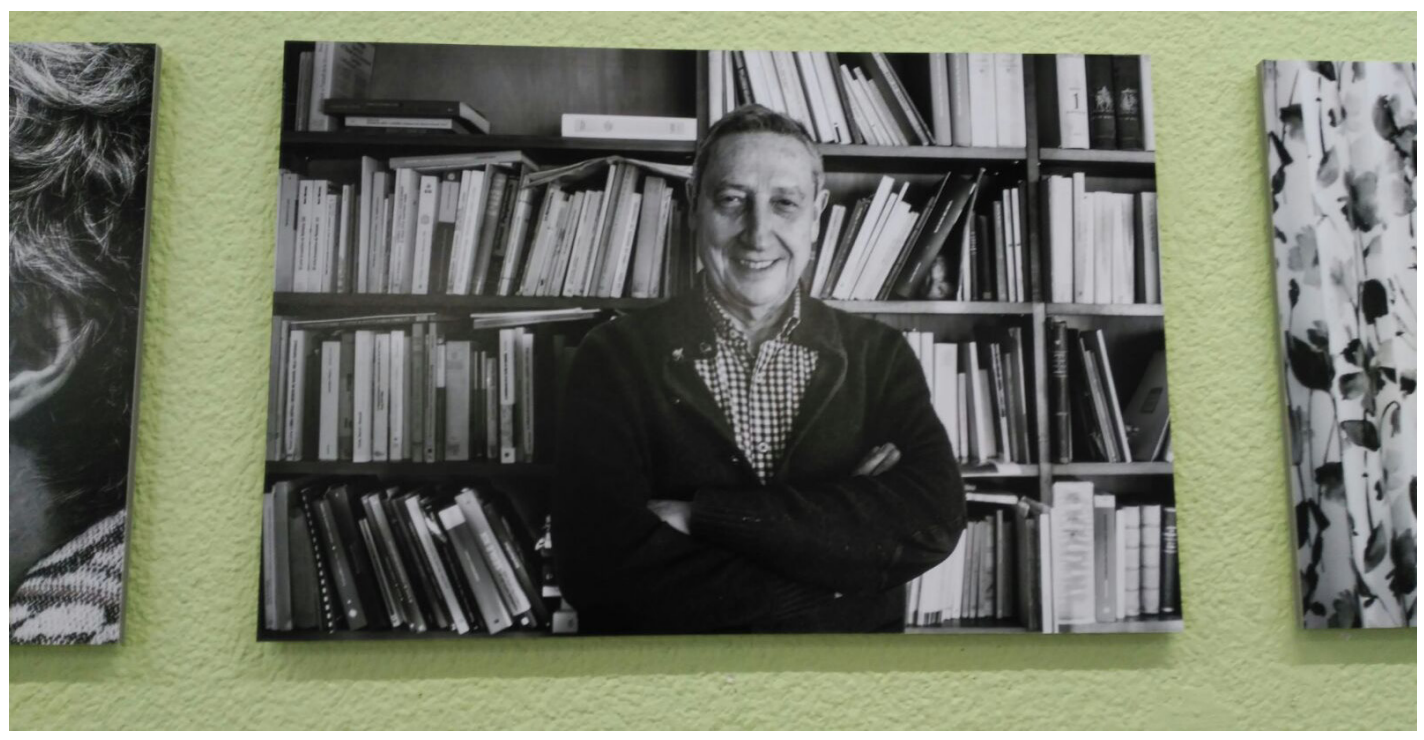


Ens podries parlar dels teus orígens familiars?

El meu pare era un obrer especialitzat, impressor -minervista i maquinista. L'any 1952-53 s'establí pel seu compte i creà una petita impremta a la Barceloneta. Morí el 1960, quan jo encara no havia fet quinze anys. La meva mare, que havia treballat en feines disperses i escadusseres, ara hagué de mantenir-nos, tota sola, a mi i a la meva germana. La principal feina que trobà fou la de la neteja al Museu d'Història de la Ciutat.

\section{Quins records tens dels teus estudis primaris i secundaris?}

A casa nostra es valorava fins a l'exageració l'educació i la cultura. Vaig estudiar les primeres lletres en una Escola Montessori i, a continuació, a l'Escola Baixeras, on vaig tenir alguns mestres que provenien de l'Institut Escola d'abans de la guerra, com Joaquim Casassas o Jaume Ministral. Del 1955 al 1962, vaig estudiar a l'Institut de Batxillerat Milà i Fontanals. Alguns professors de llavors sens dubte em van marcar. El qui més: Josep Garcia López, també procedent de l'Institut Escola, i que ens ensenyà història de la literatura. Fou ell qui primer ens parlà dels literats de la generació del 27 i també de la Segona República, de la cultura francesa del moment i, fins i tot, d'alguns escriptors catalans, com Josep M. de Sagarra o Josep Pla.

I dels anys d'universitat? És conegut que et formares inicialment com a economista...

En efecte, els meus estudis a la Universitat foren força complicats. El 1962, vaig començar Medicina. Aquell primer contacte amb la Universitat xocà de manera força estrident amb el meu accés a l'activisme cultural del moment. El 1963, volia passar-me als estudis de Filosofia i Lletres, més en l'àmbit de la literatura que no pas la història, però llavors calia tenir el batxillerat de Lletres i jo havia fet Ciències. La solució era aprovar un primer curs complet a la Universitat. Vaig triar Ciències Econòmiques. En el moment de la Caputxinada, el 1966, jo era a tercer. Vaig ser un dels estudiants expulsats de la Universitat i traslladaren el meu expedient a Bilbao. A més a més, vaig perdre la possibilitat de demanar més pròrrogues del servei militar i em tocà anar a fer-lo a Mallorca, el 1967.
I després hi va haver una tercera fase acadèmica el 1973-75, quan vaig cursar el que em faltava d'Econòmiques, de nou a Barcelona. Llavors, jo ja tenia ben dibuixat el meu camí com a historiador. La tesina, el 1975, i la tesi doctoral, el 1981, les vaig llegir a Econòmiques, però amb uns continguts clarament històrics i socials. Aquest trànsit de l'Economia a la Història ara pot semblar insòlit, però llavors els estudis d'Econòmiques, en l'especialitat d'Economia General, tenien un perfil molt marcadament social i polític.

Quins professors de la Universitat et marcaren més? N'hi va haver cap que t'inculcàs l'interès per la història contemporània?

Dels professors d'Econòmiques, he d'esmentar Jordi Nadal, Manuel Sacristán i Fabià Estapé. El contacte amb la Facultat de Ciències Econòmiques m'obrí un nou ventall de lectures que m'havien de marcar molt posteriorment. D'una banda, un apropament a la història de Catalunya, que em permeté descobrir tant Vicens Vives com Pierre Vilar i Ferran Soldevila; d'altra banda, vaig entrar també de ple en la història del pensament econòmic i social. I finalment vaig eixamplar molt el meu coneixement dels debats marxistes, des de l'austromarxisme i els autors alemanys fins als grans estudis anglosaxons (Hobsbawm, Thompson...). Ara bé, cal tenir en compte que en aquells moments la història contemporània no estava encara consolidada dins el món acadèmic a Espanya. Per aquesta precarietat, el meu accés fou molt personal, amb investigadors que vaig conèixer al marge dels cursos de la facultat, com Josep Termes i Miquel Izard. A més a més, ja al meu primer curs d'Econòmiques, vaig entrar a treballar en la confecció de l'adaptació espanyola del Larousse francès. Allà vaig consolidar les meves relacions amb l'emergent món cultural d'esquerres de Barcelona. A part dels esmentats, hi havia gent com Isidre Molas, Manolo Vázquez Montalbán o Josep Fontana, que encapçalava la secció d'Història.

Com recordes l'ambient polític i social a Barcelona durant aquells anys?

L'ambient era efervescent. Molts d'estudiants establírem una mena d'identitat entre cultura, modernitat, europeisme, esquerra política i cata- 
lanisme. Jo em vaig veure involucrat, sobretot, en el moviment estudiantil que conduí a la formació del Sindicat Democràtic d'Estudiants de la Universitat de Barcelona (SDEUB). És clar que per sota del moviment existí una forta confrontació i militància política clandestina. Jo vaig militar, a partir del 1963, dins el PSUC i vaig mantenir responsabilitats a partir del 1964 i fins al 1967 en el Comitè d'Estudiants general de la Universitat.

Com arribares a sensibilitzar-te, en concret, per la història del moviment obrer?

D'una banda, hi influïren referències familiars. Jo provenia d'una família treballadora que donà suport a la República. El record de la meva infância era plena de relats de guerra i república dels grans. El meu pare creà abans de la guerra un ateneu social a la Barceloneta, marxà voluntari al front amb la CNT, el 1939 fou tancat en un camp de concentració franquista, i després s'exilià a França; no tornà a casa fins el 1942. L'oncle es mogué sempre en l'òrbita de la UGT, l'avi matern lluità amb la columna Durruti, i la meva mare, molt jove el 1936, visqué amb els seus padrins de fonts durant la guerra, i aquest padrí, comunista, fou executat després al Camp de la Bota. També hi havia l'experiència personal. Però, a més a més, Josep Termes m'hi portà. Quan vaig anar a Mallorca, em va demanar de colllaborar en la Bibliografia dels moviments socials als Països Catalans. Això em dugué, a Palma, a les biblioteques de l'Ajuntament i a la Provincial, del carrer de Ramon Llull. Mentre consultava llibres vaig trobar-me amb premsa obrera, notòriament amb $E l$ Obrero Balear. El material i les possibilitats em van entusiasmar i, per sort meva, quan li ho vaig comentar a Josep Termes, aquest em va animar del tot a emprendre l'estudi.

El setembre de 1967 arribares a Mallorca per fer el servei militar. Com era l'ambient polític, cultural i acadèmic a l'illa?

Llavors jo no coneixia res de Mallorca. Les meves primeres portes d'entrada foren els Moll - sO- $^{-}$ bretot Francesc, l'economista-; Pere Jofre - el fill de Bernat Jofre, que havia estat batle de Palma-, i Joan Casals, propietari de l'Hotel Jaume I. Amb l'escriptor Jaume Fuster, que també feia la mili a Mallorca, aviat contactàrem amb la Casa Catalana i ens incorporàrem a l'Aula de Novel-la el 1968. Allà vaig conèixer l'escriptor Antoni Serra i la seva dona Aina Montaner, i més tard grups de persones que provenien de l'escoltisme o que feien estudis universitaris a l'Estudi General Lullià. Tot aquest ambient mantenia una afirmació cultural i ideològica antifranquista. També puc dir que vaig descobrir una riquesa lingüística insospitada en una Mallorca on el mallorquí oral era clarament dominant, encara que no hegemònic, atès que la diglòssia hi era molt present, i pocs discutien l'oficialitat del castellà.

Llavors et decidires a emprendre El moviment obver a Mallorca. En quines condicions es desenvolupà la recerca?

L'estudi em dugué uns tres anys. Potser no és sobrer recordar que en aquells moments tots els qui treballàvem aquests temes encetàvem una temàtica de recerca i quasi sempre obríem les carpetes i les caixes on el material havia estat guardat, ben sovint fora de catàleg. D'entrada, l'existència del moviment obrer mallorquí era una terra clarament ignota. La historiografia de caràcter contemporani del moment no en donava informacions, ni tan sols pistes. Vaig mantenir un contacte escadusser amb Bartomeu Barceló i potser amb Andreu Murillo. Vaig consultar les Notícies de Llabrés Bernal (encara que segons recordo sols n'havia tret llavors un primer volum). El que em fou més útil potser va ser el coneixement de petites sèries com les del Panorama Balear i les obres de geografia econòmica i social, com la de Vicenç Rosselló i Bartomeu Barceló. Amb qui vaig mantenir una relació més directa i continuada en el futur foren Gregori Mir i aviat — des de Barcelona- amb Josep Massot i Muntaner.

\section{Entrevistares algun antic militant obrer?}

Vaig poder parlar amb el socialista Andreu Crespí, amb gent de les cooperatives de Llucmajor i vaig comptar, a més, amb els records personals i coneixements de Pere Jofre. Cal tenir molt present el secretisme i la incomoditat que en aquells moments es creava quan demanaves aquesta mena d'informacions o el nom de les persones que en poguessin saber alguna cosa. En tot cas, demanar 
pels represaliats era quelcom fora de lloc, inevitablement prohibit. Com he dit abans, a casa nostra, a Barcelona, tothom tenia la seva història de guerra i la contava. En canvi, a Mallorca era un tema tabú.

Posares el límit de la recerca en el juliol de 1936. Quines raons pesaren més a l'hora de prendre aquesta decisió?

Era ben conscient de la ruptura que representà la Guerra Civil. I ben d'hora, quan encara en Massot no havia publicat el seu llibre clàssic, jo havia trobat alguns materials i la premsa dels socialistes i republicans mallorquins a Barcelona el 1936-1939. En tot cas, i al marge de la meva molt limitada dedicació a la temàtica de la repressió i la lluita i resistència en temps del franquisme, el que sí que vaig tenir i tinc sempre clar és que la història contemporània no té per què guanyar objectivitat amb el transcurs del temps. Una altra cosa són les possibilitats, els mètodes de treball i les reflexions que una història més acostada a les vivències personals de l'autor puguin exigir.

Vares col-laborar amb la revista Randa des del primer número. Com en valores els inicis?

Sincerament, crec que va afavorir l'obertura d'una etapa de la historiografia contemporània illenca nova i molt decisiva. Permeté una integració d'aportacions i recerques provinents de diverses disciplines: literatura, art, cultura, reflexió filosòfica i antropològica, geografia i història econòmica, política i social. En segon lloc, constituí, si es vol implícitament, una mena de fòrum per al debat fonamentat i pausat de la cultura catalana en general, i n'afavorí òbviament la intervenció particular de les Illes Balears. Caldria, en tot cas, recordar que la Universitat de les Illes Balears no es fundà sinó el 1978 i, lògicament, el desplegament efectiu fou posterior.

Quins objectius et vares plantejar amb la sèrie d'articles «Entorn del moviment obrer a Mallorca al segle $\mathrm{XIX} »$ ? Va implicar, al teu entendre, un canvi metodològic respecte a $E l$ moviment obver...?

Per a començar, vaig aprofitar tot un material que ja tenia en part aplegat. Em semblava que em calia fer-ho, si volia entendre millor el significat del moviment obrer del primer terç del segle xx. Canvi metodològic? Almenys en part, sí, en la mesura que per al segle XIX era fonamental assumir la centralitat del paper del republicanisme, i també la de l'anarquisme i anarcosindicalisme i el cooperativisme i mutualisme. Aquests temes ja havien estat presents en la meva història del xx (i fou, segons crec, un dels encerts d'aquell llibre procurar de situar l'obrerisme militant en el marc de la història política i social més general). Ara bé, en el meu treball a Randa no era sols això, perquè s'hi insinuaven altres reflexions més de fons a l'entorn de com acarar l'anàlisi de la cultura polític obrera i popular, trencant alguns dels clixés que establien grans ruptures i diferències entre la cultura de referència republicana i l'obrera.

Des de la segona meitat dels anys setanta, la teva recerca se centrà sobretot en Catalunya. Tot i això, continuares investigant i publicant sobre Mallorca. Com valores les teves posteriors aportacions sobre les Balears?

Jo tenia, des d'un bon començament, una dèria - crec que provenia dels meus mestres $i$, en especial, de Termes i de Fontana-, que era fer notar el paper rellevant, i a vegades central, de la realitat històrica i social del moviment obrer i popular dins la història contemporània. Una frase molt repetida per mi en aquells anys era que els historiadors del moviment obrer havíem de fer, ras i curt, història contemporània, una història social i política contemporània. Alguns ens oposàvem al que llavors semblava imperar: aillar i compartimentar els conflictes socials i el moviment obrer i popular dins algunes categories i conceptes com el d'una història social on es podia parlar de tot, excepte de la política. És a dir, ens resistíem a situar la història obrera (i la dels moviments socials) al marge d'una hipotètica història política, que en realitat sols era vista com a central i governamental.

És en aquest context que, segons penso, cal veure les meves aportacions posteriors a la història de Mallorca i les Balears. Com ja havia succeït en un principi, l'anàlisi històrica de Mallorca em permetia entrar potser més de ple, que no pas la meva recerca barcelonina, catalana o espanyola, en l'estudi global i més ambiciós de la història contem- 
porània. És el que vaig intentar de fer amb el meu capítol sobre la «Mallorca Contemporània» dins la Historia de los Pueblos de España que va coordinar Miquel Barceló i es publicà el 1984. Paral-lelament, els treballs més específics, com els relatius al socialisme illenc, incorporaven visions que jo pretenia i pretenc més complexes, provinents de la història cultural.

Com veus els vincles entre el moviment obrer català i balear en el període objecte de la teva recerca?

Més estretes del que sovint s'ha explicat, tant en el segle XIX com en el Xx, almenys, gosaria dir, fins als anys setanta. Hi incidí, és clar, la potencialitat i l'atracció de l'obrerisme barceloní, que constituí un dels pols fonamentals de les dinàmiques militants obreres de la Mediterrània occidental, no sols de l'anarcosindicalisme. Ho vaig tenir en especial en compte dins l'article «Propagandistas confederales entre el sindicato y el anarquismo. La construcción barcelonesa de la CNT en Cataluña, Aragón, País Valenciano y Baleares», publicat en la revista Ayer. Les relacions afectaren tant el moviment obrer com el republicanisme. El tema dels vincles entre les Balears i Catalunya és encara un gran espai obert a la recerca, tot i que hi hagi múltiples monografies en què s'ha tractat en profunditat.

E1 1975 t'incorporares com a professor a la Universitat Autònoma de Barcelona. Quin ambient et trobares respecte a l'estudi de la temàtica obrera?

A la UAB l'ambient era jove, amb la presència destacada a Història d'alguns dels noms que ja he esmentat abans, encapçalats per Josep Fontana (Termes i Izard, aviat passaren a la Universitat de Barcelona), i amb una sèrie de companyes i companys a Contemporània, com Anna Sallés, Irene Castells, Borja de Riquer, Francesc Bonamusa, Joaquim Nadal, Jaume Sobrequés, o Albert Balcells. De tota manera, cal dir que la nòmina de professors era a Lletres, per dir-ho així, molt transversal i variada, amb persones situades en diverses posicions metodològiques, ideològiques i polítiques. El paper i la presència als currículums del moviment obrer? Certament es tractà d'una particularitat i novetat. No passava a cap altra universitat dins d'Història. Quan hi vaig arribar, ja hi havia una assignatura denominada Historia dels Fenòmens Socials, que havia promogut Antoni Jutglar i aviat diversos professors oferírem cursos específics d'Història del Moviment Obrer. Aquesta denominació, amb petites variants, es mantingué fins a les més recents reformes dels plans d'estudi. Ara bé, cal ser conscients que aquestes línies, tot i la seva importància, no ocuparen de fet un lloc central dins els plans d'estudi d'Història a la UAB.

Quines diferències hi havia aleshores respecte a l'Europa més desenvolupada quant a l'estudi de la història del moviment obrer?

La diferència no provenia, segons el meu entendre, de la major o menor presència del tema dins les universitats. Tenia més a veure amb la força i articulació legal i institucional del moviment obrer. No oblidem quina havia estat la situació política espanyola, quan tot just es començava a recuperar la visibilitat i el reconeixement legal. En països com Anglaterra, França i Itàlia, per no parlar de les dues Alemanyes, s'havien conservat importants institucions $\mathrm{i}$ arxius documentals, $\mathrm{i}$, el que era tant o més important, els debats sobre la història del moviment obrer tenien un gran impacte social i intel-lectual. Només cal recordar el pes de les referències marxistes, socialistes i comunistes, vertebrades per centres com la Fundació Feltrinelli, l'Institut Gramsci i l'Arxiu Ernesto Ragionieri a Itàlia, o l'Institut d'Història Social de París. En canvi, la presència de la història de l'anarquisme i l'anarcosindicalisme hi era més limitada, llevat de la tasca que desenvolupava l'Institut Internacional d'Història Social d'Amsterdam.

Com ha evolucionat aquesta relació entre la historiografia espanyola sobre el moviment obrer i la de la resta d'Europa?

Ningú no pot negar la internacionalització de la historiografia catalana i espanyola que s'ha produït en les darreres dècades. Per més que, això sí, continuem en general circumscrits, i en part tancats, dins l'àmbit i els espais de l'hispanisme. Sens dubte, la internacionalització ha incidit en la historiografia obrera i social a casa nostra. En aquest sentit, ens ha afectat a tots l'evolució i el 
progressiu canvi dels paradigmes metodològics i interpretatius, fixats en gran mesura per una història social europea cada cop més marcada pels debats i les formulacions de la sociologia política i l'antropologia de matriu anglosaxona. Arribats aquí, cal valorar l'impacte i les aportacions de noves formulacions com les de la història cultural, per més que aquesta sovint ens ha arribat i arriba més aviat a través de les propostes franceses $\mathrm{i}$ italianes.

Quines han estat des d'aleshores les teves principals línies de treball en relació amb la història del moviment obrer a Espanya i Catalunya?

D'alguna manera ja ho he esmentat. Mantinc la voluntat d'entrar dins la problemàtica de la història de les cultures polítiques dels sectors populars i obrers, amb una especial insistència en les interrelacions i ús persistent de conceptes i llenguatges comuns entre els republicans i els diversos moviments obrers (sindicals, mutualistes i cooperativistes, polítics, etc.). M'interessen molt la sociabilitat, l'associacionisme i l'anàlisi de les lectures populars i militants del pensament social i polític. Darrerament, també, els aspectes simbòlics i iconogràfics, i la interrelació, més estreta que hom a vegades pensa, entre la pràctica literària i la cultura política de l'esquerra de voluntat popular i obrerista.

Per acabar. Quins projectes de recerca tens actualment en relació amb les Balears?

Potser fa de mal dir, per allò de la malastrugança. En aquests moments, la meva aspiració principal respecte a Mallorca i les
Balears és col-laborar en projectes i iniciatives d'altres. I val a dir que m'arriben notícies d'activitats i compromisos del màxim interès. Em sento molt a gust, per parlar sols d'un cas concret, de participar en la recopilació i presentació de les obres completes d'Alexandre Jaume, ara ja en fase de preparació del darrer volum. D'altra banda, espero avançar aviat en l'estudi de la literatura i el moviment demòcrata i republicà de mitjan segle XIX, tot fixant pautes i dades bàsiques a l'entorn de la presència de joves mallorquins de referència progressista a Barcelona.

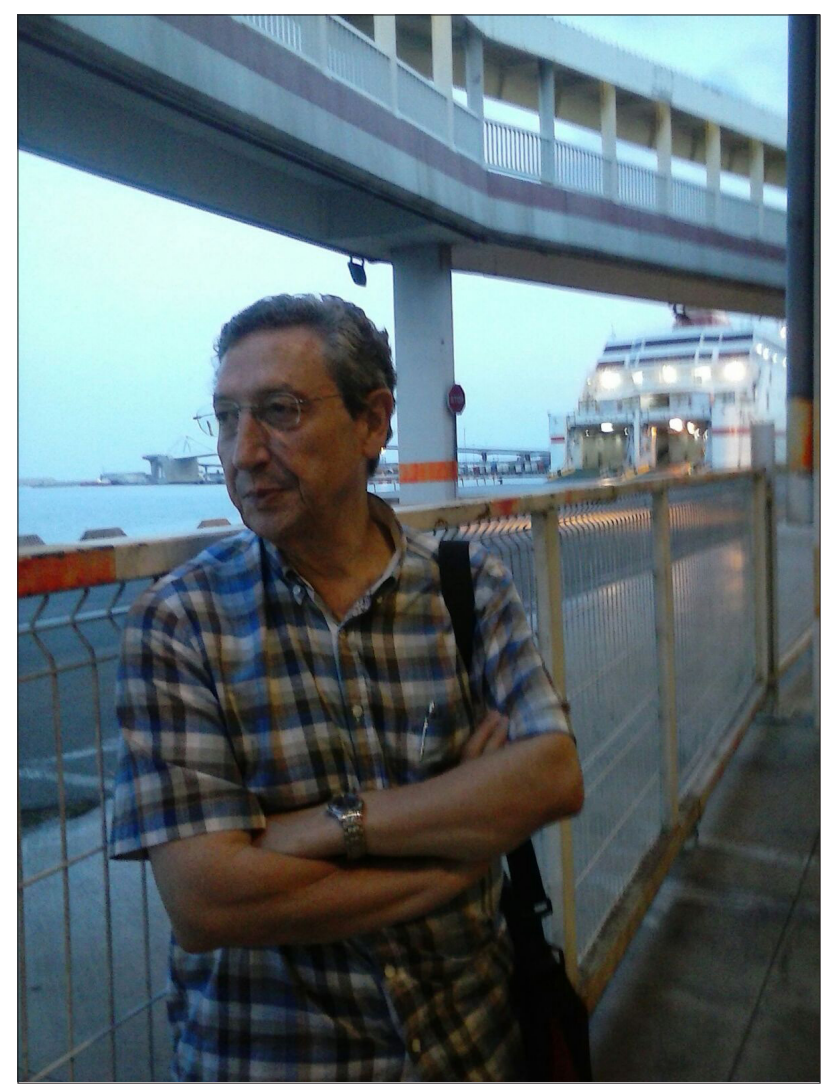

